\title{
Interfuel Substitution and Energy Use in the UK Manufacturing Sector
}

\author{
Jevgenijs Steinbuks
}

May 2010

CWPE 1032 \& EPRG 1015 


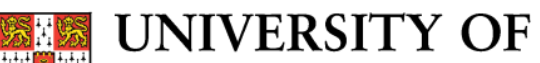 \\ CAMBRIDGE \\ Electricity Policy \\ Research Group
}

\section{Interfuel Substitution and Energy Use in the UK Manufacturing Sector}

\author{
EPRG Working Paper 1015
}

Cambridge Working Paper in Economics 1032

\section{Jevgenijs Steinbuks}

Abstract

This paper investigates interfuel substitution in the UK manufacturing sector. Econometric models of interfuel substitution are applied to energy inputs aggregated by their energy use, and separately for thermal heating processes, where interfuel substitution is technologically feasible. Compared to aggregate data, estimated own-price fuel demand elasticities for all fuels and cross-price elasticities for fossil fuels are considerably higher for thermal heating processes. Nonetheless, electricity is found to be a poor substitute for other fuels based on both aggregate data and separately for the heating process. This study also finds that an increase in real fuel prices resulted in higher substitution elasticities based on aggregate data, and lower substitution elasticities for the heating process. The results of counterfactual decomposition of change in the estimated elasticities indicate that technological change was the major determinant of the differences in observed elasticities before and after the energy price increase.

Keywords

JEL Classification
Contact

Publication

Financial Support climate change levy, elasticities, energy use, interfuel substitution, manufacturing sector, United Kingdom.

H23, Q41

js782@cam.ac.uk

May 2010

EPSRC Grant Supergen Flexnet COUNCIL 


\title{
Interfuel Substitution and Energy Use in the UK Manufacturing Sector*
}

\author{
Jevgenijs Steinbuks \\ Faculty of Economics and EPRG, University of Cambridge
}

\begin{abstract}
This paper investigates interfuel substitution in the UK manufacturing sector. Econometric models of inter-fuel substitution are applied to energy inputs aggregated by their energy use, and separately for thermal heating processes, where interfuel substitution is technologically feasible. Compared to aggregate data, estimated own-price fuel demand elasticities for all fuels and cross-price elasticities for fossil fuels are considerably higher for thermal heating processes. Nonetheless, electricity is found to be a poor substitute for other fuels based on both aggregate data and separately for the heating process. This study also finds that an increase in real fuel prices resulted in higher substitution elasticities based on aggregate data, and lower substitution elasticities for the heating process. The results of counterfactual decomposition of change in the estimated elasticities indicate that technological change was the major determinant of the differences in observed elasticities before and after the energy price increase.

Keywords: climate change levy, elasticities, energy use, interfuel substitution, manufacturing sector, United Kingdom.

JEL Classification: H23, Q41.
\end{abstract}

\section{Introduction}

The growing challenge of climate change has made economists concerned about the various ways that industries can adapt to the requirements of increasingly stringent carbon emission targets. Interfuel substitution is seen as a promising venue, as industrial consumers, which consume large amounts of energy, are expected to have greater incentives than residential or

*Financial support for this study was provided from the UK Engineering and Physical Science Research Council's research grant Supergen Flexnet. The author thanks Marco Barassi, Michael Grubb, Tim Laing, Karsten Neuhoff, David Newbery, Michael Pollitt, Richard Green, Melvyn Weeks, the anonymous referee, and the participants of Energy and Environment research seminars at the University of Cambridge and the University of Birmingham, and Supergen FlexNet General Assembly Meetings in Cardiff University for helpful comments. The author also thanks Tommy Lundgren for sharing TSP code used in Brännlund and Lundgren (2004). All remaining errors are mine. 
small commercial users to switch to non-fossil fuels (e.g. electricity from renewable energy sources), as relative fuel prices change (Jones 1995, p. 459). Starting from seminal works of Fuss (1977), Griffin (1977), Halvorsen (1977), and Pyndyck (1979), there has been a large number of econometric studies (see Barker et al 1995 for a survey) attempting to quantify the potential for switching between electricity and other fuels among industrial customers. These studies found that electricity is generally a poor substitute for other energy inputs (such as coal, oil, and gas).

Most of the existing literature on interfuel substitution is based on aggregate data, which makes existing estimates subject to a large measurement error. This happens because of the following reasons. First, studies based on the aggregate data fail to account for large differences in technological requirements for fuel types used in specific industries. For example, most cement kilns today use coal and petroleum coke as primary fuels (Peray 1998), whereas aluminum smelters are based on electrochemical operational processes (Minet 1905). Therefore, observable substitution of coal for electricity based on aggregate data may in fact reflect the exit of coal-intensive firms (e.g. manufacturers of cement), or entry of electricityintensive firms (e.g. manufacturers of aluminum). One of the few studies of interfuel substitution based on disaggregated data is Bjørner and Jensen (2002), who estimated empirical models of interfuel substitution between electricity, district heating, and two other inputs, using a micro panel dataset for Danish industrial companies. ${ }^{1}$ Their estimated cross-price elasticities of substitution for electricity were lower than in the studies based on macroeconomic data. Bjørner and Jensen (2002) interpreted this difference as an effect of 'derived demand' (or aggregation bias). ${ }^{2}$

Second, studies based on aggregate data across fuel use do not capture idiosyncratic properties of different fuels in the manufacturing processes. Waverman (1992) pointed out that fuels used by industrial sectors for non-energy purposes, such as coking coal, petrochemical feedstocks, or lubricants, have few available substitutes, and should therefore be excluded from the data. Jones (1995, p. 459) found that "excluding fuels used for non-energy purposes yields larger estimates of the price elasticities for coal and oil and indicates generally greater potential for interfuel substitution than when using aggregate data." None of the existing studies estimated the elasticities of fuel demand differentiated by fuel use for energy purposes in industrial processes. This is, however, very important because different manufacturing processes (e.g. lighting, cooling, or chemical processes) are tied to using with specific fuels

\footnotetext{
${ }^{1}$ Other notable studies based on disaggregated data are Doms (1993), Woodland (1993), Doms and Dunne (1995), Bjørner, Togeby, and Jensen (2001), and Bousquet and Ladoux (2006).

${ }^{2}$ Bjørner and Jensen (2002, p.48) define the 'derived demand' effect as a factor influencing "the relative levels of production between companies with different levels of energy use and/or distributions between various energy inputs".
} 
(typically, electricity). ${ }^{3}$

This study attempts to provide more reliable estimates of own-price and cross-price elasticities of fuel demand, that could be used for evaluating the effect of climate change policies on fuels' choice in manufacturing industries. In doing so, it excludes the consumption of fuels used in industrial processes with technological substitution possibilities limited to one or no alternative types of fuel based on the data disaggregated at both industry and the fuel use levels. Econometric models of interfuel substitution are applied to energy inputs aggregated by their energy use (high temperature thermal heating; cooling; machine drive; heating, ventilation and air conditioning; electricity generation; and electrochemical processes), and separately for high temperature thermal heating processes (which account for about 70 percent of total energy consumption), where interfuel substitution is technologically feasible. The results from 12 UK manufacturing sectors disaggregated at 4-digit SIC level between 1990 and 2005 indicate that compared to aggregate data, the own-price fuel demand elasticities for all fuels and cross-price elasticities for fossil fuels are considerably higher for thermal heating processes. Nonetheless, electricity is found to be a poor substitute to the fuels based on both aggregate data and separately for the heating process, confirming earlier findings (Barker et al 1995) that electricity is a poor technological substitute for other fuels.

This study also exploits a natural experiment of an increase in real fuel prices between 2001 and 2005 to determine whether rising energy prices result in higher substitution elasticities. The study finds higher cross-price elasticities of fuel demand based on aggregate data, and lower substitution elasticities for the heating process. These results suggest that an increase in energy prices had a limited effect on fuels' choice in the direct manufacturing process, with major substitution coming from a change in fuel demand for idiosyncratic energy-using processes, such as the machine drive, electrochemical processes, and conventional electricity generation. Counterfactual analysis is then performed to decompose observed differences in substitution elasticities. The results of the counterfactual analysis indicate that technological change was the major determinant of the differences in observed elasticities before and after the energy price increase. On the contrary, the effect of the change in economic environment (i.e. altered relative fuel prices) was limited.

\section{Empirical Specification}

The econometric specification employed in this study is the dynamic version of the linear logit model suggested by Considine and Mount (1984) and extended by Considine (1990). They argued that this functional form is better suited to satisfy the restrictions of economic theory, and is consistent with more realistic adjustment of the capital stock to input price

\footnotetext{
${ }^{3}$ This point was earlier recognized by Woodland (1993), and Bousquet and Ladoux (2006).
} 
changes. Jones (1995) and Urga and Walters (2003) compared the predictions of dynamic specifications of translog and linear logit models. Both studies concluded that a linear logit specification yields more robust results, and should therefore be preferred in the empirical analysis of interfuel substitution. ${ }^{4}$ Full derivation of the linear logit model can be found in Considine and Mount (1984) and Considine (1989). The final estimating forms and elasticity formulas are presented below.

Based on the notation from Jones (1995), and assuming that there are four fuels, a dynamic version of the system of cost-share equations derived from a linear logit model can be written as

$$
\begin{gathered}
\ln \left(\frac{S_{1}}{S_{4}}\right)_{t}=\left(\eta_{1}-\eta_{4}\right)-\left(\phi_{12}^{*} S_{2 t}^{*}+\phi_{13}^{*} S_{3 t}^{*}+\phi_{14}^{*}\left(S_{1 t}^{*}+S_{4 t}^{*}\right)\right) \ln \left(\frac{P_{1}}{P_{4}}\right)_{t} \quad(1 \mathrm{a}) \\
+\left(\phi_{12}^{*}-\phi_{24}^{*}\right) S_{2 t}^{*} \ln \left(\frac{P_{2}}{P_{4}}\right)_{t}+\left(\phi_{13}^{*}-\phi_{34}^{*}\right) S_{3 t}^{*} \ln \left(\frac{P_{3}}{P_{4}}\right)_{t}+\lambda \ln \left(\frac{Q_{1}}{Q_{4}}\right)_{t-1}+\gamma^{\prime} W_{t}+\left(\varepsilon_{1}-\varepsilon_{4}\right)_{t}, \\
\ln \left(\frac{S_{2}}{S_{4}}\right)_{t}=\left(\eta_{2}-\eta_{4}\right)-\left(\phi_{13}^{*} S_{1 t}^{*}+\phi_{23}^{*} S_{3 t}^{*}+\phi_{24}^{*}\left(S_{2 t}^{*}+S_{4 t}^{*}\right)\right) \ln \left(\frac{P_{2}}{P_{4}}\right)_{t} \quad(1 \mathrm{~b}) \\
+\left(\phi_{12}^{*}-\phi_{14}^{*}\right) S_{1 t}^{*} \ln \left(\frac{P_{1}}{P_{4}}\right)_{t}+\left(\phi_{23}^{*}-\phi_{34}^{*}\right) S_{3 t}^{*} \ln \left(\frac{P_{3}}{P_{4}}\right)_{t}+\lambda \ln \left(\frac{Q_{2}}{Q_{4}}\right)_{t-1}+\gamma^{\prime} W_{t}+\left(\varepsilon_{2}-\varepsilon_{4}\right)_{t}, \\
\ln \left(\frac{S_{3}}{S_{4}}\right)_{t}=\left(\eta_{3}-\eta_{4}\right)-\left(\phi_{13}^{*} S_{1 t}^{*}+\phi_{23}^{*} S_{2 t}^{*}+\phi_{34}^{*}\left(S_{3 t}^{*}+S_{4 t}^{*}\right)\right) \ln \left(\frac{P_{3}}{P_{4}}\right)_{t} \quad(1 \mathrm{c}) \\
+\left(\phi_{13}^{*}-\phi_{14}^{*}\right) S_{1 t}^{*} \ln \left(\frac{P_{1}}{P_{4}}\right)_{t}+\left(\phi_{23}^{*}-\phi_{24}^{*}\right) S_{2 t}^{*} \ln \left(\frac{P_{2}}{P_{4}}\right)_{t}+\lambda \ln \left(\frac{Q_{3}}{Q_{4}}\right)_{t-1}+\gamma^{\prime} W_{t}+\left(\varepsilon_{3}-\varepsilon_{4}\right)_{t} .
\end{gathered}
$$

In the system of equations $(1 a)-(1 c), Q_{i t}$ and $P_{i t}$ are fuel $i^{\prime} s$ observed quantities and prices at time $t, S_{i t}=\frac{P_{i t} Q_{i t}}{\sum_{i} P_{i t} Q_{i t}}$ are observed fuel cost shares, $S_{i t}^{*}$ are equilibrium fuel cost shares, $W_{t}$ is a vector of control variables, $\lambda$ is a parameter measuring the speed of dynamic adjustment, and $\left(\varepsilon_{i}-\varepsilon_{4}\right)_{t}$ are assumed to be normally distributed random disturbances. The model is consistently estimated using a two-step iterative procedure suggested by Considine (1990) and described in Jones (1995, p. 460). In the first step, the actual fuel cost shares

\footnotetext{
${ }^{4}$ Serletis and Shahmoradi (2008) proposed to model interfuel substitution semi-nonparametrically using two globally functional forms - the Fourier and the Asymptotically Ideal Model. Though these models could yield more robust results from theoretical perspective, their implementation is fairly complex, and it is still unclear whether the signs and the magnitudes of estimated elasticities from semi-nonparametric models yield significantly different results compared to those from translog and linear logit models.
} 
observed in each period are used in lieu of the equilibrium cost shares to estimate the parameters and produce an initial set of predicted shares for each observation. These initial predicted shares are then inserted into the model for reestimation of parameters, yielding a new set of predicted shares. This process continues until the parameter estimates converge. The nonlinear iterative seemingly unrelated estimation procedure is employed to estimate the model. ${ }^{5}$

The short-run and the long-run own-price and cross-price elasticities of fuel demand (evaluated at sample means) implied by equations $(1 a)-(1 c)$ are calculated as

$$
\begin{gathered}
E_{i i}^{S R}=\left(\phi_{i i}^{*}+1\right) \bar{S}_{i}-1, \\
E_{i j}^{S R}=\left(\phi_{i j}^{*}+1\right) \bar{S}_{j}, \text { when } i \neq j,
\end{gathered}
$$

and

$$
E_{i j}^{L R}=\frac{E_{i j}^{S R}}{1-\lambda}, \forall i, j,
$$

where $\bar{S}_{i}$ are time-invariant sample means of fuel cost shares.

\section{Data}

This study employs a new dataset using annual energy fuel consumption in the United Kingdom for the 12 most energy intensive industries from 1990 to $2005 .{ }^{6}$ The data for fuel consumption at a 4-digit Standard Industrial Classification (SIC) level comes from the UK Department of Energy and Climate Change (DECC) publication Energy Consumption in the United Kingdom. The original dataset contains consumption of seven fuels - coal, natural gas, electricity ${ }^{7}$, manufactured fuel, residual fuel oil, diesel, and liquefied petroleum gases. To avoid a collinearity problem, the consumption of the latter four fuels was aggregated into a single variable (petroleum fuels), weighted by fuel consumption in each sector. Following Jones (1995) this study excludes the consumption of fuels used for non-energy purposes. Figure 1 (Appendix II) illustrates the energy intensity of the manufacturing industries considered in this study.

\footnotetext{
${ }^{5}$ The original dynamic linear logit model was estimated in TSP. The author adapted the TSP code for estimation in STATA 10.2 using nlsur command.

${ }^{6}$ The industries and the time frame were chosen based on the data availability at the time of research.

${ }^{7}$ This study is not able to differentiate between the sources of generated electricity. Of course, it may seem that a switch from coal to coal-based electricity would do nothing to improve the situation in terms of climate change mitigation. However, a coal-using electricity generator is easier to de-carbonize than a coal-using manufacturing plant using carbon capture and storage technology.
} 
The data for nominal fuel prices and the GDP deflator to obtain real fuel prices were found in the DECC publication Quarterly Energy Prices and Energy Trends. The energy prices incorporate the 2001 Climate Change Levy (CCL).

The following control variables are used to account for specification bias:

- Real sector gross value added, in logarithms (Office for National Statistics, Annual Business Inquiry): this variable is employed to account for unobserved structural changes in the economy, which affect the manufacturing sectors' fuel intensity.

- A combined heating and power system (CHP) dummy variable (DECC CHP database, http://chp.decc.gov.uk): industries using combined heating and power systems use fuels more efficiently (yielding higher own-price and cross-price elasticities).

- A time trend: a proxy for efficiency gains or exogenous technical change in the UK industrial fuel consumption.

- A dummy variable accounting for an unexplained upwards structural shift in coal consumption in the cement sector in $2001 .^{8}$

- Battese-Nerlove dummy variables to account for corner solutions arising when fuel cost share ratios are zero or very close to zero. ${ }^{9}$

- Sector-specific dummy variables to control for unobserved fixed effects.

Table A.1 (Appendix 1) shows the descriptive statistics for the explanatory variables used in the model specified by equations $(1 a)-(1 c)$.

This study is the first to incorporate distributions of fuel use in manufacturing processes in the econometric analysis of interfuel substitution. Unfortunately, the data for distribution of fuel use in the UK manufacturing sector were not available at the time of the research. This study therefore uses comparable data ${ }^{10}$ from the U.S. Energy Information Administration Manufacturing Energy Consumption Survey (MECS). ${ }^{11}$

Table 1 shows the distribution of fuel use across six major manufacturing processes. Only the high-temperature thermal heating process, which accounts for about 70 percent of total

\footnotetext{
${ }^{8}$ Based on author's communication with DECC, a possible explanation of this shift could be related to changes in sampling and aggregation methods.

${ }^{9}$ For details, see Battese (1997).

${ }^{10}$ Because the distribution of fuel use in the UK manufacturing processes does not exist, direct benchmarking between two datasets are not possible. Indirect tests indicate comparable distributions of aggregate fuel use and sectors' energy intensity and capital-energy ratios in UK and US manufacturing.

${ }^{11}$ The survey is administered every four years. All other observations were obtained through extrapolation. The measurement error from extrapolation is low because the distribution of fuel use across manufacturing processes is highly persistent.
} 
energy consumption, uses all fuels. As regards other processes, electrochemical and machine drive processes use electric power. Coal and natural gas are used in electricity generation, whereas electricity and natural gas are used in cooling, and heating ventilation and air conditioning (HVAC) processes. The economic theory provides two alternative explanations for absence of certain fuel's use by manufacturing firms. The first explanation, advocated by Woodland (1993), and Bjørner and Jensen (2002), treats consumed fuel patterns as purely exogenous because of supply constraints (e.g. natural gas and district heating are not available to all industrial companies) or technological constraints (e.g. certain types of production process can only be carried out with one type of fuel). The second explanation, proposed by Lee and Pitt (1987), and Bousquet and Ivaldi (1998), is based on the assumption that all types of energy can be used in manufacturing, and the technology is flexible enough to allow for substitutions between all energy forms. Observed zero fuel consumptions reflect deliberate choices of manufacturing firms and are the outcomes of firms' cost minimization behavior leading to corner solutions. ${ }^{12}$

Table 1: Fuel Use in Manufacturing Processes in 2002

\begin{tabular}{|l|c|c|c|c|c|}
\hline \multicolumn{1}{|c|}{ Process / Fuel } & $\begin{array}{c}\text { Share of Total } \\
\text { Consumption* }\end{array}$ & Coal & Natural Gas & $\begin{array}{c}\text { Petroleum } \\
\text { Products }\end{array}$ & Electricity \\
\hline Heating & $71 \%$ & $16 \%$ & $71 \%$ & $4 \%$ & $9 \%$ \\
\hline Cooling & $2 \%$ & $0 \%$ & $21 \%$ & $0 \%$ & $79 \%$ \\
\hline Machine Drive & $16 \%$ & $0 \%$ & $5 \%$ & $0 \%$ & $95 \%$ \\
\hline $\begin{array}{l}\text { Heating, Ventilation, and } \\
\text { Air Conditioning }\end{array}$ & $5 \%$ & $0 \%$ & $57 \%$ & $1 \%$ & $42 \%$ \\
\hline Electricity Generation & $5 \%$ & $5 \%$ & $94 \%$ & $1 \%$ & $0 \%$ \\
\hline $\begin{array}{l}\text { Electrochemical Processes } \\
\text { (including Lighting) }\end{array}$ & $1 \%$ & $0 \%$ & $0 \%$ & $0 \%$ & $100 \%$ \\
\hline
\end{tabular}

Following Woodland (1993), and Bjørner and Jensen (2002), this study treats observed zero fuel consumption patterns in each manufacturing process as purely exogenous. No electricity consumption for electricity generation and sole electricity consumption for electrochemical process is exogenous by process definition. Zero coal and petroleum products' consumption for cooling, machine drive, and HVAC is typically driven by technological constraints. $^{13}$ Also, as noted by Bjørner and Jensen (2002, p.31) and supported by MECS data, the fuel consumption patterns are remarkably stable over time across manufacturing

\footnotetext{
${ }^{12}$ Bousquet and Ladoux (2006) demonstrate that estimated elasticies are highly sensitive to assumed flexibility of the technological substitution between different fuels.

${ }^{13}$ Source: author's interviews with mechanical engineers and industry professionals during Supergen FlexNet General Assembly Meetings in Cardiff University.
} 
processes. ${ }^{14}$ The analysis of interfuel substitution based on aggregate data thus reflects both the substitution among different fuels within particular manufacturing process (mainly high-temperature thermal heating process $^{15}$ ) and the substitution between different manufacturing processes.

\section{Results}

Table A.2 (Appendix 1) presents the parameter estimates and summary statistics for a dynamic linear logit model applied to aggregate fuel consumption and separately to fuel consumption for heating processes. Both models have a reasonably good fit, characterized by high pseudo-R squares, though the model applied to the heating process has fewer observations $^{16}$, lower log-likelihood and larger standard errors. Estimates for structural parameters $\phi_{i j}^{*}$ tend to be higher for the model estimated for heating processes, indicating higher elasticities. The models' estimates of the adjustment parameter $\lambda$ reveals that fuel demand is responsive in the short-run with about $65 \%$ of the long-run response taking place in the same year as a price change. The size of the adjustment parameter is slightly higher for the model estimated for thermal heating processes, but the difference is not statistically significant.

As regards other explanatory variables, the coefficients of the logarithm of real gross value added are negative and significant across the equations, indicating structural shifts away from fossil fuels to electricity. The coefficients of the dummy variable for combined heating and power systems are negative but not statistically significant (with one exception), indicating that industries with CHPs are slightly more electricity-intensive. Finally, the estimated coefficients for the time trend are negative for coal-electricity and oil-electricity ratios, and positive (but not statistically significant) for the natural gas-electricity ratio. These results indicate that the direction of the technological change in fuel choice is from petroleum products and coal to natural gas and electricity. ${ }^{17}$

\footnotetext{
${ }^{14}$ Of course, it does not mean that some types of processes will not be associated with certain fuels in the future because there is no relationship between them now. Analysis of firms' and industries'choice of future fuel technologies is extremely complex because of large uncertainty, and is well beyond the scope of this paper.

${ }^{15}$ It follows from Table 1 that there is some scope for substitution between natural gas and electricity in cooling and HVAC processes. The analysis for these two processes is trivial, and is not reported here. The results are available upon request.

${ }^{16}$ This is because fuel use distribution for the pharmaceuticals sector was available only for 2002 .

${ }^{17}$ As the time trend is a fairly crude proxy for technological change, one should interpret the magnitude of estimated coefficients with caution. In the next section this study uses natural experiment from an increase in fossil fuel prices to capture the relative magnitude of the technological change. An alternative approach not pursued here is to construct more sophisticated measure of technological change (see e.g. Baltagi and Griffin, 1988).
} 


\subsection{All Processes}

Table 2 (columns 2 and 3 ) shows the estimated short-run and long-run price elasticities of fuel demand evaluated at the sample means for aggregate fuel consumption. All of the estimated own-price elasticities are statistically significant at the $1 \%$ level. Estimated elasticities have expected signs and reasonable magnitudes comparable to the results from earlier studies based on the aggregate data. ${ }^{18}$ The demand for all fuels is highly inelastic in both the shortand long-run. As expected, electricity is the most inelastic energy service, with estimated elasticity of -0.11 in the short run, and -0.16 in the long run. The demand for fossil fuels is

slightly more elastic with estimated short-run elasticities ranging between -0.16 (for natural gas) to -0.36 (for coal), and long-run elasticities - between -0.24 to -0.54 .

Table 2: Price Elasticities for Models of Fuel Consumption , 1990-2005

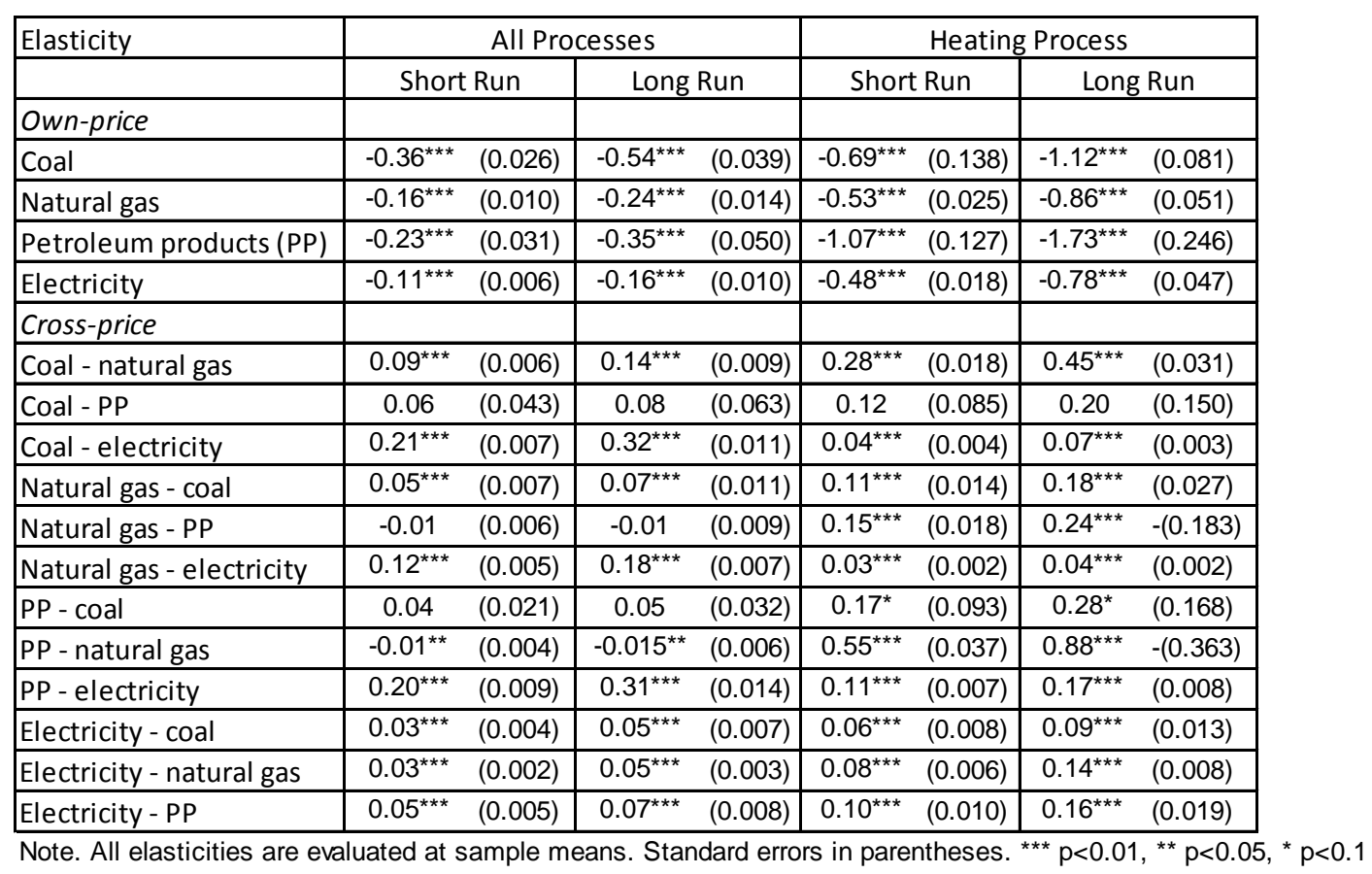

Estimated cross-price elasticities (except for natural gas - petroleum products) are positive, indicating that fuels or fuel-using manufacturing processes are substitutes. These elasticities are however small, and in some cases (natural gas - petroleum products, coal petroleum products, and petroleum products - coal) are not statistically significant. The largest and statistically significant values of estimated cross-price elasticities are for coal in response to electricity prices $(+0.21$ in the short-run and +0.32 in the long-run), and for

\footnotetext{
${ }^{18}$ For a summary of earlier elasticity estimates, see Table 3.3 in Barker et al (1995, p.68). Also see Stern (2009).
} 
petroleum products with respect to electricity prices $(+0.20$ in the short-run and +0.31 in the long-run).

\subsection{Thermal Heating Process}

Table 2 (columns 4 and 5) shows the estimated short-run and long-run price elasticities of fuel demand evaluated at the sample means for the thermal heating process. The fuels' response to energy prices becomes considerably larger. For petroleum products, the demand is elastic in both short- and the long-run with own-price elasticities being about five times higher compared to aggregate data (-1.07 in the short-run and -1.73 in the long-run). The demand for coal is inelastic in the short-run, and elastic in the long-run, and own-elasticities of coal demand are about two times higher compared to aggregate data (-0.69 in the shortrun and -1.12 in the long-run). For natural gas and electricity, the demand is inelastic, but own-price elasticities are about three times higher compared to aggregate data $(-0.48$ and -0.53 in the short-run, and -0.78 and -0.86 in the long-run). All of the estimated own-price elasticities are statistically significant at a $1 \%$ level.

All cross-price elasticities of fuel demand in heating processes are positive, indicating that fuels are substitutes. Estimated cross-price elasticities are statistically significant (except for coal - petroleum products, and petroleum products - coal). Compared to the results from aggregate data, almost all cross-price elasticities are larger. The largest response is for petroleum products with respect to natural gas prices $(+0.55$ in the short-run and +0.88 in the long-run), and for coal with respect to natural gas prices $(+0.28$ in the short-run and +0.45 in the long-run). However, estimated cross-price elasticities of all fossil fuels with respect to electricity prices are smaller for heating process as compared to aggregate data. Though estimated cross-price elasticities of electricity with respect to fossil fuel prices are larger for heating process as compared to aggregate data, they are still very small $(+0.06$ to +0.10 in the short-run, and +0.09 to +0.16 in the long-run). These results indicate that while fossil fuels are better substitutes in heating processes, they are still very poor substitutes to electricity.

\section{Effect of a Rise in Energy Prices on Interfuel Substitution}

In April 2001 the UK Government implemented the Climate Change Levy (CCL) - a charge on energy usage for business and the public sector, introduced to encourage energy efficiency and help the UK meet its legally binding commitment to reduce greenhouse gas emissions. Introduction of the CCL resulted in drastic increases in end-use fossil fuel prices for indus- 
trial customers (see Figure 2, Appendix II). ${ }^{19}$ Also, because of tight oil market fundamentals and increased demand for energy products, real energy prices for all fuels apart from coal increased drastically between 2001 and 2005 (International Energy Agency 2006). An increase in real fuel prices between 2001 and 2005 is a simple natural experiment that can be exploited to determine how rising energy prices affect substitution elasticities. ${ }^{20}$ Ideally, one would like to compare two periods before and after price increase. This analysis cannot be implemented here because the sample between 2001 and 2005 is too short to yield reasonable estimates. This study therefore attempts to quantify the effect of energy price increases on interfuel substitution in UK manufacturing, by comparing the econometric models' estimates for the full sample, and between 1990 and 2000, when real fuel prices were flat or falling, and acknowledging that the effect of energy prices on substitutability is likely to be higher than estimated difference. ${ }^{21}$ Table A.3 (Appendix 1) illustrates the results of the estimation of the dynamic linear model for the sample between 1990 and 2000. A Chow (1960) test for structural breaks indicates that the difference in the estimated coefficients for full and restricted samples is statistically significant (see Table A.3, Appendix 1). ${ }^{22}$

Table 3 shows the estimated elasticities from econometric models of interfuel substitution between 1990 and 2000. The left-hand side of Table 3 illustrates estimated elasticities based on aggregate data. Estimated own-price elasticities for all fuels are lower, compared to the results for the full sample in Table 2, and are statistically significant at a $1 \%$ level. This result is consistent with previous findings that energy demand is more elastic when energy prices increase (Gately and Huntington 2002, Griffin and Schulman 2005, Adeyemi and Hunt 2007). Estimated cross-price elasticities are also higher for the full sample data (except for petroleum products with respect to electricity prices), with several fuels reversing from complements to substitutes. The differences in estimated cross-price elasticities for the two samples are small, indicating that increase in fuel prices had limited effect on interfuel

\footnotetext{
${ }^{19} \mathrm{~A}$ number of energy-intensive industries considered in this study received an 80 percent reduction in the CCL but committed to imminent measures to achieve drastic reduction in carbon emissions by 2020 . This raised the shadow price of discounted CCL close to actual (undiscounted) CCL. Also, electricity generated from co-generation schemes (CHP) was exempt from the CCL. Unfortunately, the information on the share of electricity generated from CHP was not available.This study therefore incorporates actual CCL, and acknowledges that short-run own-price elasticities of fossil fuels' demand may be slightly biased upwards. The author thanks Michael Grubb for making these points.

${ }^{20}$ Hall $(1983,1986)$ used similar approach to analyze the changes in industrial sector fuel price elasticities following major oil price shocks in 1973-1974 and 1979. Contrary to this study, Hall's analysis was restricted to aggregate level data and it did not attempt to find out what were the sources of change in substitution elasticities.

${ }^{21}$ The author thanks Marco Barassi and Richard Green for making this point.

${ }^{22}$ The sample between 2001 and 2005 was too short to estimate elasticities for the period of price increases for the heating process. Therefore, for the heating process, Chow test for predictive failure was implemented by constructing pulse dummy variables for each year after the price increase, and using a Wald test to determine their joint significance, as suggested by Pesaran, Smith and Yeo (1985).
} 
substitution.

The right-hand side of Table 3 shows the results from econometric models of interfuel substitution for the heating process. Contrary to the results from aggregate data, estimated own-price elasticities for all fuels are higher (though the difference is not statistically significant, except for electricity), compared to the results for the full sample in Table 2. Estimated cross-price elasticities also tend to be lower for the full sample model, except for coal-natural gas, natural gas - coal, and petroleum products-natural gas elasticities. These results suggest that an increase in energy prices had a limited effect on fuels' choice in the direct manufacturing process, with major substitution coming from changes in fuel demand for idiosyncratic energy-using processes, such as the machine drive, electrochemical processes, and conventional electricity generation.

Table 3: Price Elasticities for Models of Fuel Consumption, 1990-2000

\begin{tabular}{|c|c|c|c|c|}
\hline \multirow[t]{2}{*}{ Elasticity } & \multicolumn{2}{|c|}{ All Processes } & \multicolumn{2}{|c|}{ Heating Process } \\
\hline & Short Run & Long Run & Short Run & Long Run \\
\hline \multicolumn{5}{|l|}{ Own-price } \\
\hline Coal & $-0.11^{\star \star}(0.052)$ & $-0.17^{\star \star}(0.086)$ & $-0.75^{\star \star \star}(0.053)$ & $-1.38^{\star \star \star}(0.105)$ \\
\hline Natural gas & $-0.04^{\star \star *}(0.014)$ & $-0.07^{\star \star \star}(0.023)$ & $-0.58^{\star \star *}(0.032)$ & $-1.08^{\star \star \star}(0.059)$ \\
\hline Petroleum products (PP) & $-0.17^{\star \star \star}(0.023)$ & $-0.28^{\star \star \star}(0.036)$ & $-1.09^{\star \star *}(0.036)$ & $-2.02^{\star * \star}(0.072)$ \\
\hline Electricity & $-0.08^{\star \star \star}(0.009)$ & $-0.13^{\star \star \star}(0.014)$ & $-0.76^{\star \star \star}(0.017)$ & $-1.40^{\star \star \star}(0.034)$ \\
\hline \multicolumn{5}{|l|}{ Cross-price } \\
\hline Coal - natural gas & $-0.02(0.415)$ & $-0.04(0.528)$ & $0.21^{\star \star *}(0.038)$ & $0.38^{\star \star \star}(0.070)$ \\
\hline Coal - PP & $-0.005(0.043)$ & $-0.009(0.080)$ & $0.17^{* \star *}(0.019)$ & $0.31^{\star \star \star}(0.037)$ \\
\hline Coal - electricity & $0.14^{\star \star \star}(0.027)$ & $0.22^{\star \star *}(0.045)$ & $0.14^{\star \star *}(0.009)$ & $0.25^{\star \star \star}(0.017)$ \\
\hline Natural gas - coal & $-0.01^{*}(0.007)$ & $-0.02^{*}(0.011)$ & $0.09^{\star \star \star}(0.022)$ & $0.16^{\star \star \star}(0.041)$ \\
\hline Natural gas - PP & $-0.04^{* \star *}(0.007)$ & $-0.07^{\star \star *}(0.012)$ & $0.17^{\star \star \star}(0.021)$ & $0.31^{* \star *}(0.039)$ \\
\hline Natural gas - electricity & $0.09^{\star \star \star}(0.012)$ & $0.15^{\star \star *}(0.020)$ & $0.09^{\star \star \star}(0.007)$ & $0.16^{\star \star \star}(0.013)$ \\
\hline PP - coal & $-0.003(0.003)$ & $-0.005(0.005)$ & $0.20^{\star \star \star}(0.031)$ & $0.38^{\star \star *}(0.058)$ \\
\hline PP - natural gas & $-0.04^{* * *}(0.004)$ & $-0.07^{* \star *}(0.007)$ & $0.49^{\star \star \star}(0.040)$ & $0.91^{\star \star \star}(0.077)$ \\
\hline PP - electricity & $0.22^{\star \star \star}(0.020)$ & $0.35^{\star \star \star}(0.032)$ & $0.16^{\star \star \star}(0.011)$ & $0.29^{\star \star \star}(0.020)$ \\
\hline Electricity - coal & $0.01^{* \star *}(0.005)$ & $0.02^{\star \star *}(0.008)$ & $0.15^{\star \star \star}(0.020)$ & $0.28^{\star \star \star}(0.038)$ \\
\hline Electricity - natural gas & $0.02^{\star \star \star}(0.003)$ & $0.03^{\star \star *}(0.004)$ & $0.23^{\star \star \star}(0.017)$ & $0.42^{\star \star \star}(0.032)$ \\
\hline Electricity - PP & $0.04^{\star \star \star}(0.008)$ & $0.07^{\star \star \star}(0.013)$ & $0.14^{\star \star \star}(0.016)$ & $0.26^{\star \star \star}(0.030)$ \\
\hline
\end{tabular}

The analysis above compares elasticities evaluated at different sample means and different flexibility of substitution parameters $\phi$. Therefore, it does not allow us to determine whether the change in substitution between different fuels was due to a change in economic conditions (change in relative fuel prices) or due to technological change (change in flexibility of substitution parameter $\phi$ ). To assess the effect of economic conditions and technological change on elasticities of substitution between different fuels, this study follows Frondel and Schmidt (2006) and uses counterfactual relative fuel prices instead of observed relative fuel 
prices. This approach allows us to investigate which cross-price elasticities of fuel demand would result if the relative fuel prices were different from actual prices, while the technology in use remained the same. The counterfactual analysis is based on the famous OaxacaBlinder (Oaxaca 1973, Blinder 1973) decomposition of wage differences applied to the case of dynamic linear logit function:

$$
\eta_{i j}\left(\phi^{1}, \bar{p}^{1}\right)-\eta_{i j}\left(\phi^{0}, \bar{p}^{0}\right)=\left[\eta_{i j}\left(\phi^{1}, \bar{p}^{1}\right)-\eta_{i j}\left(\phi^{1}, \bar{p}^{0}\right)\right]+\left[\eta_{i j}\left(\phi^{1}, \bar{p}^{0}\right)-\eta_{i j}\left(\phi^{0}, \bar{p}^{0}\right)\right]
$$

where $\phi^{1}$ and $\phi^{0}$ are the coefficients from equations $(1 a)-(1 c)$ estimated from full and restricted samples, and $\bar{p}^{1}$ and $\bar{p}^{0}$ are full and restricted sample means of fuel prices. Then $\eta_{i j}\left(\phi^{1}, \bar{p}^{1}\right)$ and $\eta_{i j}\left(\phi^{0}, \bar{p}^{0}\right)$ are corresponding cross-price elasticities, evaluated at full and restricted samples, and $\eta_{i j}\left(\phi^{1}, \bar{p}^{0}\right)$ is a counterfactual cross-price elasticity. If estimated parameters $\phi^{1}$ and $\phi^{0}$ reflect the state of technology in periods 0 and 1 respectively, then the first bracketed term on the right-hand side of the decomposition (5) captures the variation in elasticities as relative prices change for the same state of technology. This term can also be interpreted as the movement along firm's isoquant following change in relative prices conditional on technology in period 0 . The second bracketed term represents the movement across firm's isoquants holding prices fixed, and yields "genuine differences in structure or technology" (Frondel and Schmidt 2006, p.189). ${ }^{23}$

Table 4: Decomposition of the Difference between Cross-Price Elasticities of Interfuel Substitution for 1990-2000 and 1990-2005 (All Processes)

\begin{tabular}{|l|c|c|c|c|c|c|}
\hline Cross-Price Elasticity & $\eta\left(\phi^{1}, \bar{p}^{1}\right)$ & $\eta\left(\phi^{0}, \bar{p}^{0}\right)$ & $\eta\left(\phi^{1}, \bar{p}^{1}\right)-\eta\left(\phi^{0}, \bar{p}^{0}\right)$ & $\eta\left(\phi^{1}, \bar{p}^{0}\right)$ & $\eta\left(\phi^{1}, \bar{p}^{1}\right)-\eta\left(\phi^{1}, \bar{p}^{0}\right)$ & $\eta\left(\phi^{1}, \bar{p}^{0}\right)-\eta\left(\phi^{0}, \bar{p}^{0}\right)$ \\
\hline & & & & & & \\
\hline Coal - natural gas & 0.090 & -0.024 & 0.114 & 0.077 & 0.013 & 0.101 \\
\hline Coal - PP & 0.055 & -0.005 & 0.061 & 0.052 & 0.003 & 0.057 \\
\hline Coal - electricity & 0.211 & 0.137 & 0.075 & 0.228 & -0.016 & 0.091 \\
\hline Natural gas - coal & 0.048 & -0.012 & 0.060 & 0.040 & 0.008 & 0.052 \\
\hline Natural gas - PP & -0.008 & -0.040 & 0.032 & -0.008 & -0.001 & 0.033 \\
\hline Natural gas - electricity & 0.121 & 0.095 & 0.026 & 0.130 & -0.009 & 0.036 \\
\hline PP - coal & 0.036 & -0.003 & 0.039 & 0.029 & 0.006 & 0.032 \\
\hline PP - natural gas & -0.010 & -0.044 & 0.035 & -0.008 & -0.001 & 0.036 \\
\hline PP - electricity & 0.204 & 0.220 & -0.016 & 0.219 & -0.016 & -0.001 \\
\hline Electricity - coal & 0.030 & 0.015 & 0.015 & 0.025 & 0.005 & 0.010 \\
\hline Electricity - natural gas & 0.032 & 0.020 & 0.012 & 0.028 & 0.005 & 0.008 \\
\hline Electricity - PP & 0.045 & 0.042 & 0.003 & 0.042 & 0.003 & -0.0001 \\
\hline
\end{tabular}

\footnotetext{
${ }^{23}$ Frondel and Schmidt (2006) point out that proposed decomposition is not unique, and it varies with particular choice of baseline technology parameter $\phi$ and the baseline prices $\bar{p}$. Alternative decompositions are equally plausible but they may yield different results in absolute value. The value added by counterfactual decomposition relies on the proportions of the total change in observed elasticities due to technological change versus those due to altered economic conditions, not on the magnitudes of each term.
} 
Table 4 illustrates the results of the decomposition (5) for the differences in cross-price elasticities of fuel demand from Tables 2 and 3 for aggregate data. The second, third and fourth columns of Table 4 show estimated elasticities for full and restricted samples, and their difference. The fifth column shows the counterfactual elasticity evaluated at restricted sample means of fuel prices. The sixth and seventh columns of Table 4 show the changes in estimated elasticities from changes in relative fuel prices, and differences in structure of technology respectively. It follows from Table 4 that altered relative fuel prices (column 6 ) generally had a small effect on the size of cross-price elasticities, whereas technological change (column 7) was the major factor behind increased substitutability among fuels. Furthermore, for some pairs of fuels (coal - electricity, natural gas - petroleum products, natural gas electricity, petroleum products-natural gas) changes in production technologies appear to be even more important than one might presume on the sole basis of the difference between observed cross-price elasticities. The effect of altered fuel prices was, however, not trivial for electricity substitution with respect to fossil fuel prices. Altered fuel prices also fully explained the fall in cross-price elasticity for petroleum products demand with respect to electricity prices.

Table 5: Decomposition of the Difference between Cross-Price Elasticities of Interfuel Substitution for 1990-2000 and 1990-2005 (Heating Process)

\begin{tabular}{|l|c|c|c|c|c|c|}
\hline Cross-Price Elasticity & $\eta\left(\phi^{1}, \bar{p}^{1}\right)$ & $\eta\left(\phi^{0}, \bar{p}^{0}\right)$ & $\eta\left(\phi^{1}, \bar{p}^{1}\right)-\eta\left(\phi^{0}, \bar{p}^{0}\right)$ & $\eta\left(\phi^{1}, \bar{p}^{0}\right)$ & $\eta\left(\phi^{1}, \bar{p}^{1}\right)-\eta\left(\phi^{1}, \bar{p}^{0}\right)$ & $\eta\left(\phi^{1}, \bar{p}^{0}\right)-\eta\left(\phi^{0}, \bar{p}^{0}\right)$ \\
\hline Coal - natural gas & & & & & & \\
\hline Coal - PP & 0.280 & 0.208 & 0.073 & 0.258 & 0.022 & 0.051 \\
\hline Coal - electricity & 0.124 & 0.168 & -0.043 & 0.144 & -0.019 & -0.024 \\
\hline Natural gas - coal & 0.045 & 0.135 & -0.090 & 0.052 & -0.007 & -0.083 \\
\hline Natural gas - PP & 0.109 & 0.088 & 0.021 & 0.110 & -0.001 & 0.022 \\
\hline Natural gas - electricity & 0.151 & 0.170 & -0.019 & 0.175 & -0.024 & 0.005 \\
\hline PP - coal & 0.026 & 0.087 & -0.061 & 0.030 & -0.004 & -0.057 \\
\hline PP - natural gas & 0.174 & 0.205 & -0.031 & 0.176 & -0.002 & -0.029 \\
\hline PP - electricity & 0.545 & 0.489 & 0.056 & 0.502 & 0.043 & 0.013 \\
\hline Electricity - coal & 0.106 & 0.158 & -0.052 & 0.123 & -0.017 & -0.034 \\
\hline Electricity - natural gas & 0.057 & 0.149 & -0.092 & 0.058 & -0.001 & -0.092 \\
\hline Electricity - PP & 0.085 & 0.227 & -0.142 & 0.078 & 0.007 & -0.148 \\
\hline
\end{tabular}

Table 5 shows the results of the decomposition (5) for the differences in cross-price elasticities of fuel demand from Tables 2 and 3 for the heating processes, and its columns have the same interpretation as in Table 4. As mentioned above, substitutability between fuels within the heating processes improved only for three combinations of fuels (coal-natural gas, natural gas - coal, and petroleum products-natural gas). Though the effect of technological change was positive for all three pairs of fuels, altered economic conditions were relatively important for two out three pairs (coal-natural gas and petroleum products-natural gas). 
The effect of technological change was also positive for the cross-price elasticity of natural gas demand with respect to petroleum products, and the decline in cross-price elasticity was explained by altered economic conditions. Both altered economic conditions and technological change affected the decline in substitutability in coal - petroleum products, petroleum products - electricity, and electricity - petroleum products pairs of fuels. For all other pairs of fuels technological change was the major determinant of the decline in substitutability among fuels.

The results from Tables 4 and 5 indicate that technological change was the major determinant of the differences in observed elasticities for 1990 - 2005 and 1990 - 2000. These results support earlier findings of Griffin and Schulman (2005) that observed asymmetric response to energy prices is a proxy for technological change. However, the direction of technological change was different when the elasticities were estimated for aggregate data and the heating processes. For aggregate data, technological change resulted in greater substitutability between fuels, possibly because of efficiency improvements in non-heating processes. ${ }^{24}$ For heating process, the technological change resulted in smaller substitutability between fuels. This is an interesting and perhaps counter-intuitive finding, whose explanation is left for further research. The results also indicate that the operational response (i.e. the choice of different fuels given specific production technology / process) to rising fuel prices is small. The major reason for the change in interfuel substitution in manufacturing is from energy efficiency improvements in fuel-using capital stock across different technologies and production processes.

\section{Conclusions}

This study contributes to the large literature on interfuel substitution in manufacturing by focusing on fuels' use in manufacturing processes. Earlier studies have recognized that excluding fuels used for non-energy purposes and have few available substitutes significantly improves the estimates of fuel demand elasticities. This study takes a step further by recognizing that fuels used for some energy purposes are also idiosyncratic and should also be excluded from econometric analysis of interfuel substitution. The econometric models of interfuel substitution are estimated based on the data for all energy processes, and separately for thermal heating processes (which account for about 70 percent of total energy consumption), where interfuel substitution is technologically feasible. Excluding the consumption of fuels with limited technological substitution possibilities yields more reliable estimates of

\footnotetext{
${ }^{24}$ For a hypothetical example, let us assume that rising electricity prices result in efficiency improvements and a decline in electricity consumption for machine drive, holding other things constant. Though fuel consumption is not changed for thermal heating process, aggregate data would still reflect a decline in ratio of electricity to other fuels, i.e. greater substitutability between electricity and other fuels.
} 
own-price and cross-price elasticities of fuel demand. Specifically, the results from 12 UK manufacturing sectors disaggregated at 4-digit SIC level between 1990 and 2005 indicate that compared to aggregate data, the own-price fuel demand elasticities for all fuels and cross-price elasticities for fossil fuels are considerably higher for thermal heating processes. Nonetheless, electricity is found to be a poor substitute to fuels based on both aggregate data and separately for the heating processes.

This study also finds that an increase in real fuel prices resulted in higher substitution elasticities based on aggregate data, and lower substitution elasticities for the heating process. These results suggest that an increase in energy prices had a limited effect on fuels' choice in the direct manufacturing process, with major substitution coming from change in fuel demand for idiosyncratic energy-using processes, such as the machine drive, electrochemical processes, and conventional electricity generation. The results of counterfactual decomposition of change in the estimated elasticities indicate that technological change was the major determinant of the differences in observed elasticities before and after the energy price increase. On the contrary, the effect of the change in economic environment (i.e. altered relative fuel prices) was limited.

These results have important implications for energy and climate policies. Rising fossil fuel costs will have a larger effect on substitution from carbon-intensive coal and petroleum products to less carbon-intensive natural gas, and a small effect for substitution from fossil fuels to electricity in the UK manufacturing sector. Raising fuel prices will also result in somewhat higher substitutability across fuels through technology-induced adjustment in idiosyncratic energy-using manufacturing processes. Unfortunately, the data limitations made it difficult to give a precise magnitude of the change in substitutability following an increase in fossil fuel prices. In future research it is important to address this issue by re-estimating the model for longer time-series following an increase in fossil fuel prices from 2001 and comparing substitution elasticities before and after price changes.

\section{References}

[1] Adeyemi, O.I., and L. C. Hunt. 2007. "Modelling OECD Industrial Energy Demand: Asymmetric Price Responses and Energy-saving Technical Change." Energy Economics, vol. 29(4), pp. 693-709.

[2] Baltagi, B.H., and J.M. Griffin. 1988. "A General Index of Technical Change." The Journal of Political Economy, vol. 96(1), pp. 20-41.

[3] Barker, T., P. Ekins, and N. Johnstone. 1995. Global Warming and Energy Demand, Routledge, Taylor \& Francis Group. 
[4] Battese, G.E. "A Note on the Estimation of Cobb-Douglas Production Functions when Some Explanatory Variables Have Zero Values." Journal of Agricultural Economics, vol. 48 , pp. $250-252$.

[5] Bjørner, T.B., M. Togeby, and H.H. Jensen. 2001. "Industrial Companies' Demand for Electricity: Evidence from a Micro-panel." Energy Economics vol. 23, pp. 595-617.

[6] Bjørner, T.B., and H.H. Jensen. 2002. "Interfuel Substitution within Industrial Companies: An Analysis Based on Panel Data at Company Level." The Energy Journal, vol. 23, pp. 27-50.

[7] Blinder, A.S. 1973. "Wage Discrimination: Reduced Form and Structural Estimates." The Journal of Human Resources, vol. 8(4), pp. 436-455.

[8] Bousquet, A., and M. Ivaldi. 1998. "An Individual Choice of Energy Mix." Resource and Energy Economics, vol. 20, pp. 263-286.

[9] Bousquet, A., and N. Ladoux. 2006. "Flexible versus Designated Technologies and Interfuel Substitution." Energy Economics, vol. 28, pp. 426-443.

[10] Brännlund, R., and T. Lundgren. 2004. "A Dynamic Analysis of Interfuel Substitution for Swedish Heating Plants." Energy Economics, vol. 26, pp. 961-976..

[11] Chow, G.C. 1960. "Tests of Equality between Subsets of Coefficients in Two Linear Regression Models." Econometrica, vol. 28, pp. 591-605.

[12] Considine, T. J., 1989. "Separability, Functional Form and Regulatory Policy in Models of Interfuel Substitution." Energy Economics, vol. 11, pp. 89-94.

[13] Considine., T. J., 1990. "Symmetry Constraints and Variable Returns to Scale in Logit Models." Journal of Business and Economic Statistics, vol. 8, pp. 347-353.

[14] Considine, T.J., and T.D. Mount. 1984. "The Use of Linear Logit Models for Dynamic Input Demand Systems." The Review of Economics and Statistics, vol. 66, pp. 434443.

[15] Doms, M.E. 1993. "Interfuel Substitution and Energy Technology Heterogeneity in U.S. Manufacturing." Center for Economic Studies Working Paper, vol. 93(5).

[16] Doms, M.E., and T. Dunne. 1995. "Energy Intensity, Electricity Consumption, and Advanced Manufacturing-Technology Usage." Technological Forecasting and Social Change, vol. 49(3), pp. 297-310(14).

[17] Frondel, M. and C. Schmidt. 2006. "The Empirical Assessment of Technology Differences: Comparing the Comparable." The Review of Economics and Statistics 88(1), $186-192$. 
[18] Fuss, M.A. 1977. "The Demand for Energy in Canadian Manufacturing: an Example of the Estimation of Production Function with Many Inputs". Journal of Econometrics vol. 5, pp. 89-116.

[19] Gately, D. and H. Huntington. 2002. "The Asymmetric Effects of Changes in Price and Income on Energy and Oil Demand." The Energy Journal, vol. 23(1), pp. 19-56.

[20] Griffin, J.M. 1977. "Inter-fuel Substitution Possibilities: a Translog Application to Intercountry Data." International Economic Review, vol. 18(3), pp. 755-770.

[21] Griffin, J. and C. Schulman. 2005. "Price Asymmetry: A Proxy for Energy Saving Technical Change?" The Energy Journal, vol. 26(2), pp. 1-21.

[22] Hall, V.B. 1983. "Industrial Sector Interfuel Substitution Following the First Major Oil Shock." Economics Letters, vol. 12, pp. 377-382.

[23] Hall, V.B. 1986. "Industrial Sector Fuel Price Elasticities Following the First and Second Major Oil Price Shocks." Economics Letters, vol. 20, pp. 79-82.

[24] Halvorsen, R. 1977. "Energy Substitution in U.S. Manufacturing," Review of Economics and Statistics, vol. 59(4), pp. 381-388.

[25] International Energy Agency. 2006. World Energy Outlook. OECD / IEA, Paris.

[26] Jones, C.T. 1995. "A Dynamic Analysis of Interfuel Substitution in U.S. Industrial Energy Demand." Journal of Business 83 Economic Statistics, vol. 13, pp. 459-465.

[27] Lee, L.F., and M.M. Pitt. 1987. "Microeconometric Models of Rationing, Imperfect Markets, and Non-negativity Constraints." Journal of Econometrics, vol. 36, pp. $89-110$.

[28] Minet, A. 1905. The Production of Aluminum and Its Industrial Use, translated by L. Waldo, New York, London: John Wiley \& Sons, Chapman \& Hall.

[29] Oaxaca, R.L. 1973. "Male-Female Wage Differentials in Urban Labor Markets." International Economic Review, vol. 14(3), pp. 693-709.

[30] Pesaran, M.H., R.P. Smith and J.S. Yeo. 1985. "Testing for Structural Stability and Predictive Failure: a Review." Manchester School, vol. 53, pp. 280-295.

[31] Peray, K.E. 1998. The Rotary Cement Kiln, CHS Press.

[32] Pindyck, R.S. 1979. "Interfuel Substitution and the Industrial Demand for Energy: an International Comparison." The Review of Economics and Statistics, vol. 61, pp. 169-179. 
[33] Serletis A., and A. Shahmoradi. 2008. "Semi-nonparametric Estimates of Interfuel Substitution in U.S. Energy Demand." Energy Economics 30, vol. 2123-2133.

[34] Stern, D.I. 2009. "Interfuel Substitution: A Meta-Analysis." EERH Research Report No. 33, June 2009.

[35] Urga, G., and C. Walters. 2003. "Dynamic Translog and Linear Logit Models: a Factor Demand Analysis of Interfuel Substitution in US Industrial Energy Demand." Energy Economics vol. 25, pp. 1-21.

[36] Waverman, L. 1992. "Econometric Modelling of Energy Demand: When are Substitutes Good Substitutes?" in Energy Demand: Evidence and Expectations, D. Hawdon, Ed. London: Academic Press.

[37] Woodland, A.D. 1993. "A Micro-econometric Analysis of the Industrial Demand for Energy in NSW", The Energy Journal, vol. 14(2), pp. 57-89. 


\section{Appendix I - Tables}

Table A.1: Descriptive Statistics, 1990-2005

\begin{tabular}{|c|l|c|c|c|}
\hline Variable & \multicolumn{1}{|c|}{ Variable Description } & Units & Mean & $\begin{array}{c}\text { Standard } \\
\text { Deviation }\end{array}$ \\
\hline$P_{1}$ & Fuel price: Coal & $f /$ toe $^{*}$ & 0.65 & 0.40 \\
\hline$P_{2}$ & Fuel price: Natural Gas & $f /$ toe & 0.54 & 0.14 \\
\hline$P_{3}$ & Fuel price: Petroleum Products & $f /$ toe $^{*}$ & 1.04 & 0.48 \\
\hline$P_{4}$ & Fuel Price: Electricity & $f /$ toe $^{*}$ & 2.63 & 0.43 \\
\hline$Q_{1}$ & Fuel Quantity: Coal & ktoe $^{* *}$ & 204 & 333 \\
\hline$Q_{2}$ & Fuel Quantity: Natural Gas & ktoe & 374 & 359 \\
\hline$Q_{3}$ & Fuel Quantity: Petroleum Products & ktoe $^{* *}$ & 320 & 614 \\
\hline$Q_{4}$ & Fuel Quantity: Electricity & ktoe & 271 & 155 \\
\hline$Y$ & Sector Gross Value Added & $f$ million* & 2040 & 1803 \\
\hline$C H P$ & Combined Heating and Power System & binary & 0.50 & 0.50 \\
\hline
\end{tabular}

* Variables are expressed in real terms, using 1990 as a reference year.

** ktoe stands for thousand tonnes of oil equivalent (toe) 
Table A.2: Results for Models of Fuel Consumption, 1990-2005

\begin{tabular}{|l|l|l|l|l|}
\hline & \multicolumn{2}{|l|}{ All Processes } & \multicolumn{2}{l|}{ Heating Process } \\
\hline Parameter & coeff. & s.e. & coeff. & s.e. \\
\hline$\eta_{1}-\eta_{4}$ & 3.83 & $(1.21)$ & 5.93 & $(1.76)$ \\
\hline$\eta_{2}-\eta_{4}$ & 0.62 & $(0.93)$ & 5.68 & $(1.54)$ \\
\hline$\eta_{3}-\eta_{4}$ & -0.53 & $(2.92)$ & -3.02 & $(3.55)$ \\
\hline$\phi_{12}^{*}$ & -0.45 & $(0.29)$ & -0.27 & $(0.32)$ \\
\hline$\phi_{13}^{*}$ & -0.59 & $(2.70)$ & 0.17 & $(5.65)$ \\
\hline$\phi_{14}^{*}$ & -0.65 & $(0.12)$ & -0.62 & $(0.16)$ \\
\hline$\phi_{23}^{*}$ & -1.06 & $(0.27)$ & 0.42 & $(0.62)$ \\
\hline$\phi_{24}^{*}$ & -0.80 & $(0.08)$ & -0.78 & $(0.12)$ \\
\hline$\phi_{34}^{*}$ & -0.67 & $(0.17)$ & -0.09 & $(0.23)$ \\
\hline$\lambda$ & 0.34 & $(0.03)$ & 0.38 & $(0.04)$ \\
\hline$\alpha_{1} \ln Y$ & -0.52 & $(0.14)$ & -0.63 & $(0.20)$ \\
\hline$\alpha_{2} \ln Y$ & -0.07 & $(0.20)$ & -0.53 & $(0.17)$ \\
\hline$\alpha_{3} \ln Y$ & -0.03 & $(0.10)$ & 0.24 & $(0.54)$ \\
\hline$\beta_{1}$ CHP & 0.003 & $(0.01)$ & -0.48 & $(0.80)$ \\
\hline$\beta_{2} C H P$ & -0.73 & $(0.16)$ & -0.01 & $(0.04)$ \\
\hline$\beta_{3} C H P$ & -0.30 & $(0.19)$ & -0.45 & $(0.32)$ \\
\hline$\gamma_{1} t$ & -0.06 & $(0.01)$ & -0.04 & $(0.02)$ \\
\hline$\gamma_{2} t$ & 0.02 & $(0.01)$ & 0.02 & $(0.01)$ \\
\hline$\gamma_{3} t$ & -0.04 & $(0.02)$ & -0.02 & $(0.02)$ \\
\hline Summary Statistics & & & \\
\hline Obs. & 177 & & 166 & \\
\hline pseudo- $R_{1}^{2}$ & 0.87 & & 0.75 & \\
\hline pseudo- $R_{2}^{2}$ & 0.81 & & 0.81 & \\
\hline pseudo- $R_{3}^{2}$ & 0.83 & & 0.87 & \\
\hline Log lik. & -319.23 & -513.34 \\
\hline
\end{tabular}

Note. Estimates for Battese-Nerlove, fixed-effect, and structural shift dummy variables are not reported, and available upon request. 
Table A.3: Results for Models of Fuel Consumption, 1990-2000

\begin{tabular}{|l|l|l|l|l|}
\hline & \multicolumn{2}{|l|}{ All Processes } & \multicolumn{2}{l|}{ Heating Process } \\
\hline Parameter & coeff. & s.e. & coeff. & s.e. \\
\hline$\eta_{1}-\eta_{4}$ & 2.63 & $(1.59)$ & 3.96 & $(2.89)$ \\
\hline$\eta_{2}-\eta_{4}$ & 1.54 & $(1.50)$ & 4.54 & $(3.05)$ \\
\hline$\eta_{3}-\eta_{4}$ & 0.46 & $(6.60)$ & -1.39 & $(1.79)$ \\
\hline$\phi_{12}^{*}$ & -1.17 & $(3.54)$ & -0.41 & $(0.83)$ \\
\hline$\phi_{13}^{*}$ & -1.04 & $(0.81)$ & 0.36 & $(0.53)$ \\
\hline$\phi_{14}^{*}$ & -0.79 & $(0.39)$ & -0.01 & $(0.01)$ \\
\hline$\phi_{23}^{*}$ & -1.32 & $(0.39)$ & 0.38 & $(0.62)$ \\
\hline$\phi_{24}^{*}$ & -0.86 & $(0.22)$ & -0.36 & $(0.28)$ \\
\hline$\phi_{34}^{*}$ & -0.67 & $(0.35)$ & 0.16 & $(0.13)$ \\
\hline$\lambda$ & 0.38 & $(0.04)$ & 0.47 & $(0.05)$ \\
\hline$\alpha_{1} \ln Y$ & -0.37 & $(0.17)$ & -0.53 & $(0.30)$ \\
\hline$\alpha_{2} \ln Y$ & -0.17 & $(0.19)$ & -0.51 & $(0.34)$ \\
\hline$\alpha_{3} \ln Y$ & -0.15 & $(0.35)$ & 0.001 & $(0.004)$ \\
\hline$\beta_{1} C H P$ & 0.02 & $(0.78)$ & -1.54 & $(0.85)$ \\
\hline$\beta_{2} C H P$ & -0.60 & $(0.18)$ & -0.10 & $(0.23)$ \\
\hline$\beta_{3} C H P$ & 0.02 & $(0.12)$ & -0.92 & $(0.32)$ \\
\hline$\gamma_{1} t$ & -0.07 & $(0.01)$ & -0.09 & $(0.02)$ \\
\hline$\gamma_{2} t$ & 0.01 & $(0.01)$ & 0.01 & $(0.01)$ \\
\hline$\gamma_{3} t$ & -0.05 & $(0.02)$ & -0.03 & $(0.03)$ \\
\hline Summary Statistics & & & & \\
\hline Obs. & 120 & & 110 & \\
\hline pseudo- $R_{1}^{2}$ & 0.93 & & 0.84 & \\
\hline pseudo- $R_{2}^{2}$ & 0.80 & & 0.79 & \\
\hline pseudo- $R_{3}^{2}$ & 0.80 & & 0.91 & \\
\hline Log lik. & -184.69 & -285.75 \\
\hline Chow test $\left(\chi^{2}(N), p>\chi^{2}\right)$ & 315.5 & $(0.00)$ & 34.03 & $(0.00)$ \\
\hline & \multicolumn{5}{|l}{} \\
\hline
\end{tabular}

Note. Estimates for Battese-Nerlove, fixed-effect, and structural shift dummy variables are not reported, and available upon request. 


\section{Appendix II - Figures}

Figure 1: Energy Intensity in UK Manufacturing in 2005

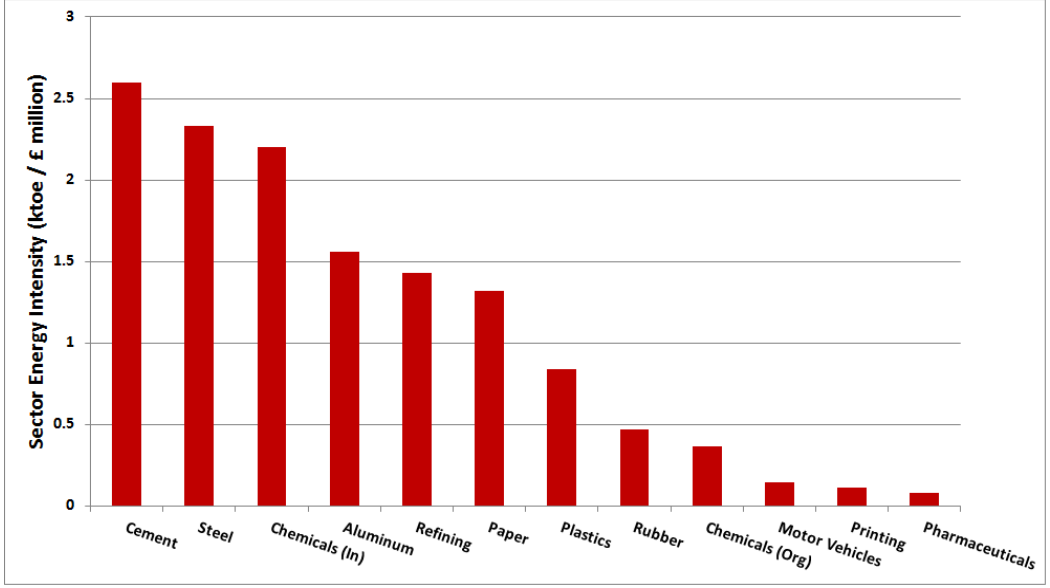

Figure 2: Real Fuel Prices in UK Manufacturing, 1990-2005

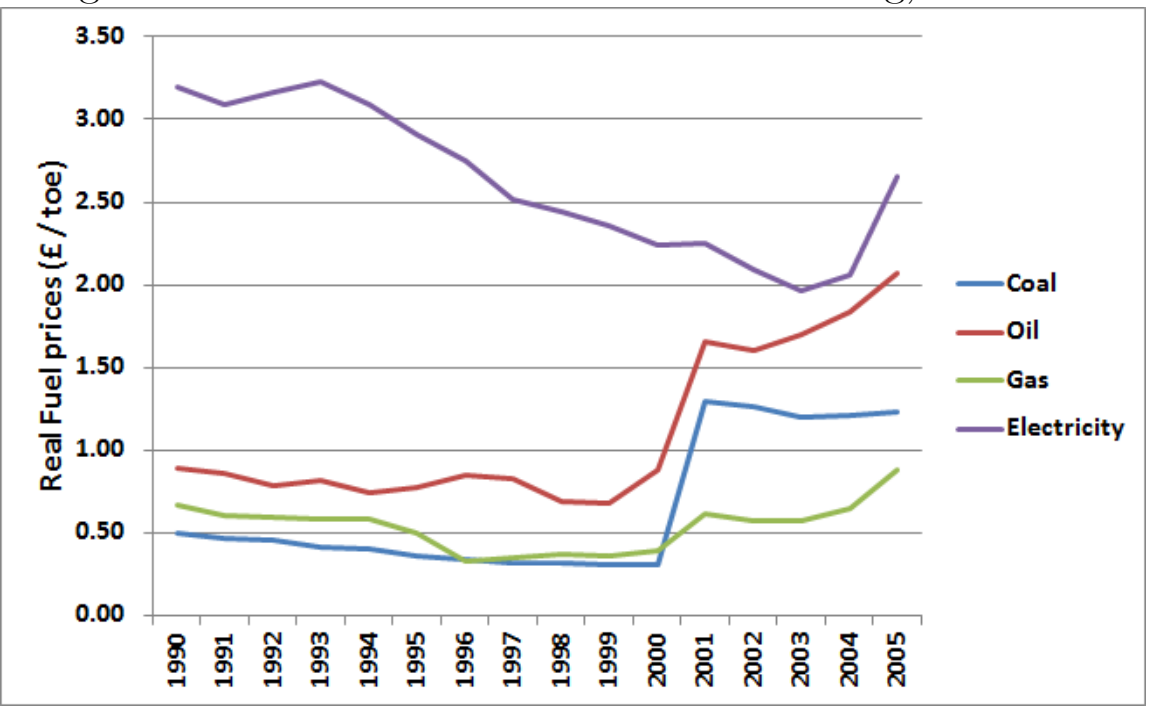

